\title{
QUALIDADE DE VIDA EM SAÚDE: AVALIAÇÃO DE UMA POPULAÇÃO CARCERÁRIA FEMININA DO ESTADO DE SÃO PAULO
}

\section{QUALITY OF LIFE IN: EVALUATION OF A FEMALE PRISON POPULATION IN THE STATE OF SÃO PAULO}

\author{
Vera Lúcia Ignácio Molina ${ }^{1}$ \\ Mariângela Faggionato dos Santos ${ }^{2}$
}

RESUMO: $A$ avaliação foi realizada por meio de uma entrevista e, em seguida, o questionário SF-36 foi respondido por 99 mulheres. Como a abordagem é quantitativa, foram utilizados os recursos disponíveis do MiniTab e do teste Qui-Quadrado de Aderência. A dimensão Capacidade Funcional, numa escala de zero a 100, que foi de 26,23, indica que as AVDs e as AIVDs, são igualmente prejudicadas. Os aspectos físicos (6.667) são abalados pelos aspectos emocionais (4.505), sociais (10.051), de saúde mental (8.848) e saúde geral (21.923), e influenciam a dor (6.667). O Estado Geral de Saúde (21.923) revela que as mulheres têm saúde precária. Aprisionadas aumentam as oportunidades de riscos em relação à vulnerabilidade ao estresse, à não satisfação, à fadiga crônica, à ansiedade e à baixa estima. Esses fatores podem vir acompanhados de desconforto emocional significativo e podem aumentar a probabilidade de problemas comportamentais, o que justificaria o baixo índice de Saúde Mental (8,848). O aspecto emocional (4.505) demonstra que elas vivenciaram emoções negativas, levando seus corpos físicos a um estado de estagnação, e, com isso, o surgimento de doenças psicossomáticas torna-se propício. Os Sociais (10.051) não favorecem a sociabilidade no contexto. A dimensão da dor (6.667), embora irrelevante, revela que a qualidade de vida em saúde é insatisfatória, uma vez que são baixos os índices relativos à saúde mental, aos físicos, aos emocionais e à capacidade funcional. A correlação entre capacidade funcional e aspectos físicos e entre os físicos e emocionais é positiva, com significância estatística. A correlação positiva e sem significância estatística foi encontrada nas doze relações realizadas. $A$ correlação negativa, com significância estatística, foi encontrada entre: capacidade funcional e saúde mental; capacidade funcional e dor; aspectos físicos e dor; aspectos emocionais e dor. A correlação negativa e sem significância estatística foi encontrada entre capacidade funcional e saúde geral e capacidade funcional e dor. $A$ qualidade de vida das presidiárias não é saudável, e os domínios mais comprometidos são a saúde mental, o aspecto físico, e o aspecto emocional. Em relação à dor, apresenta-se elevado, mas, quando relacionado às demais dimensões, revela um amortecimento da estrutura afetiva.

Palavras-chave: qualidade de vida em saúde; sistema prisional; estudo de gênero.

ABSTRACT: The evaluation was made through an interview, followed by an SF questionnaire - 36 were answered by 99 women. As the approach is quantitative, the resources used were the Mini-tab and the ChiSquare Adherence. The Functional Capacity dimension on a scale from zero to 100 was 26.23. This indicates that the AVDs (daily life activities) and AIVDs (Instrumental activities of daily life) are equally affected. The physical aspects $(6,667)$ are affected by the emotional aspects (4,505), social aspects $(10,051)$, and general health $(21,923)$ and pain $(6,667)$. The General State of Health $(21,923)$ indicates that the women have poor health. Female prisoners have a higher risk in relation to stress vulnerability, dissatisfaction, chronic tiredness, anxiety, and low self-esteem. These factors can be associated with significant emotional discomfort and can increase the probability of behavioral problems, which would explain the low Mental Health index (8.848). The emotional aspect $(4,505)$ shows that they live with negative emotions, leading their physical bodies to a stagnant state, which makes acquiring new psychosomatic illnesses easier. The Social aspects $(10,051)$ do not help create a sociable context. The pain dimension (6,667), although irrelevant, reveals that quality of life in health is unsatisfactory, because mental, physical, and emotional health, as well as functional capacity indexes are low.

\footnotetext{
${ }^{1}$ Docente da Faculdade de Odontologia de São José dos Campos - UNESP; Faculdade de Ciências da Saúde - UNIVAP. Email: vlim@uol.com.br.

${ }^{2}$ Docente da Faculdade de Ciências da Saúde - UNIVAP. E-mail: mfaggionato@bol.com.br.
} 
The correlation between the functional capacity and the physical aspects, and between the physical and the emotional aspects are positive, and statistically significant. The positive and statistically insignificant correlation was found in the twelve relationships performed. A statistically significance negative correlation was found between: functional capacity and mental health; functional capacity and pain; physical aspects and pain; emotional aspects and pain. The negative and insignificant correlation was found between functional capacity and general health and functional capacity and pain. Female prisoners' quality of life is not healthy, and the areas most compromised are mental health and the physical and emotional aspects. In relation to pain, the index is high, but when compared to the other dimensions it indicates a numbing in the affective structure.

Keywords: life quality in health; prison system; gender study.

\section{INTRODUÇÃO}

O Instituto CASA DA MULHER apresentou à direção de um presídio feminino do estado de São Paulo uma proposta para levantar $o$ interesse $e$ as expectativas das mulheres em regime prisional e propor atividades para geração de renda.

O sistema carcerário, construído para homens, não é um espaço físico adequado às mulheres que cometem delitos. A estrutura carcerária não conta com política pública no atendimento às especificidades do gênero feminino.

Reconhece-se a necessidade de adaptações nos presídios que passam a receber a população feminina, pois essa população possui necessidades diferenciadas às dos homens.

(...) Mas, apesar das mulheres estarem detidas em estabelecimentos separados, as instalações não possuem estrutura adequada para elas; a vasta maioria das penitenciárias e cadeias foi "adaptada" de penitenciárias e cadeias públicas masculinas existentes. Exemplo disso é que apenas uma das penitenciárias femininas visitadas dispunha de berçário adequado para as mulheres cuidarem de seus bebês (MORAES, 2008).

Além das adaptações, há o problema da superlotação carcerária, que agrava a situação das penitenciárias sem estrutura adequada para o recebimento de mulheres grávidas ou com algum tipo de doença. Assim, como no sistema prisional masculino, as mulheres detentas ficam aglomeradas em celas pequenas e sem suporte social.

A expectativa é a organização de um sistema carcerário específico para o gênero feminino, que atenda suas necessidades. Mulheres menstruam todos os meses, precisam de tratamento pré-natal e de prevenções de doenças, como câncer de mama, entre outras demandas.

Para Moraes (2008):

(...) apesar da proteção detalhada dada aos presos por meio da lei internacional e nacional, as mulheres encarceradas enfrentam sérias dificuldades para ter acesso à assistência à saúde adequada. As mulheres entrevistadas reclamaram de uma série de problemas por falta de tratamento de saúde, variando desde aqueles relativamente menores até os que requerem cuidado especializado e urgente. Os impedimentos para que as mulheres recebam o cuidado necessário à saúde são: ausência 
de profissionais da área da saúde; falta de assistência ginecológica; escassez de medicamentos; precárias instalações de assistência à saúde; e falta de pessoal para a assistência especializada.

O sistema

carcerário

masculino/feminino precisa contar não apenas com espaço físico: sua dinâmica deve contemplar campanhas de prevenção à saúde, acompanhamento médico, incentivo ao convívio familiar, assim como visitas de familiares e parentes.

Em se tratando de mulheres gestantes, é imprescindível não só o acompanhamento pré-natal, mas também berçário para recebimento dos recémnascidos no período da amamentação, e acompanhamento da criança por um médico especializado.

Assim, percebe-se que o sistema carcerário feminino deixa a desejar em sua estrutura e em relação ao atendimento especializado às mulheres, e precisa ser revisto e reformulado.

Diante desse cenário, e no cumprimento de sua missão, o Instituto CASA DA MULHER buscou conhecer o universo feminino para 'oportunizar vivências e discussões a respeito da realidade do mundo feminino, que levem as mulheres a se tornarem protagonistas de suas histórias'.

Essa missão respalda-se na visão para os próximos anos de atuação do Instituto: 'Ser um espaço de referência possibilitador da expressão das potencialidades do universo feminino'.

Os valores e crenças que justificam e fundamentam as atividades a serem propostas para as mulheres encarceradas são: cliente satisfeito; acolhimento garantido; pessoas comprometidas e realizadas; qualidade no que faz; empreendedorismo responsável; respeito à condição feminina; integridade da condição feminina; crescimento psicossocial e rentabilidade das realizações.

A atividade exploratória, com dinâmica de integração, palestras, espaço de conversação, dinâmica para o levantamento das necessidades e expectativas, e aplicação do Teste Qualidade de Vida em Saúde SF-36, foi desenvolvida no segundo semestre de 2010. A proposta de intervenção está prevista para o primeiro semestre de 2011, aos sábados e quinzenalmente.

Além dessas razões, que justificam este estudo, foi avaliada a qualidade de vida em saúde de noventa e nove mulheres encarceradas, a partir do protocolo SF-36 (WARE; SHERBOURNE, 1992), que veio a se somar às múltiplas avaliações até então realizadas no cenário nacional, para que se obtivesse, num futuro próximo, a avaliação da qualidade de vida em saúde do cidadão brasileiro.

\section{REVISÃO DE LITERATURA}

A Qualidade de Vida no Trabalho e na Saúde passou a ser um objetivo perseguido pela cúpula estratégica das organizações, tornando-se objeto de interesse das grandes corporações nos dias atuais, tanto no setor fabril como no setor de prestação de serviços.

Neste momento, a qualidade é 
encarada como um conjunto de atributos essenciais à sobrevivência das organizações, sejam elas produtoras de bens ou prestadoras de serviços, grandes, médias ou micro. $\mathrm{O}$ mercado, particularmente o de prestação de serviços, se encontra altamente competitivo, e a gerência estratégica deve buscar o diferencial na gestão da qualidade. Essa tendência chega ao seu clímax nos primeiros anos do século XXI.

A qualidade de vida no trabalho, segundo Aguiar (2000), deve ter como meta a geração de uma organização mais humanizada, em que o trabalho envolva relativo grau de responsabilidade e de autonomia no que se refere ao cargo, recebimento de recursos, feedback do desempenho, tarefas adequadas, variedade, enriquecimento do trabalho e ênfase no desenvolvimento pessoal do indivíduo.

Para Seidl e Zannon (2004), o conceito da qualidade de vida envolve duas vertentes: a) a primeira é a linguagem cotidiana, usada pela população em geral e profissionais de várias áreas, mas principalmente aqueles ligados às políticas públicas; b) a segunda é do universo da pesquisa científica em diferentes campos do saber. Minayo, Hartz e Buss (2000, p. 8) afirmam que a "qualidade de vida é uma noção eminentemente humana que tem sido aproximada ao grau de satisfação encontrado na vida familiar, amorosa, social e ambiental e à própria estética existencial." Para Biff (2006), a criação de políticas de saúde, a formação de profissionais e a criação de instrumentos de avaliação de saúde buscam contribuir para a qualidade de vida dos cidadãos.
Dentro desse contexto teórico, a Organização Mundial da Saúde (OMS) define a qualidade de vida em saúde como a "percepção que uma pessoa tem da sua vida, no contexto do sistema de valores e da cultura em que vive; em relação às suas metas, expectativas e padrões e interesses" (MANZIERE, 2006).

Nos dias de hoje, a melhoria na qualidade de vida se dá com o estilo e a situação de vida. Assim, a confiabilidade em novos hábitos e atitudes, a busca da felicidade e da satisfação pessoal no ambiente profissional, social, fisiológico, emocional, e espiritual, em equilíbrio, são indicadores de qualidade de vida (MINAYO, 2000, apud BRAMANTE, 1996). É de se presumir que o ambiente de compra-venda deva favorecer e fortalecer esse equilíbrio harmonioso.

O conceito 'Qualidade de Vida' contém múltiplos significados e abrange uma variedade de dimensões, entretanto essa complexidade tem apenas um foco, que é referir-se ao método utilizado para medir as condições da vida do ser humano, envolvendo o bem-estar físico, mental, psicológico e emocional, além dos relacionamentos sociais com a família e amigos, e também a saúde, educação, poder de compra e outras circunstâncias da vida.

Há consenso, entre alguns autores, em relação ao fato de as organizações formais, produtoras de bens e serviços, contarem com programas de qualidade de vida. Entre tantos se encontra Limongi França (2003), que revela num estudo realizado com os profissionais ligados à gestão de pessoas, que $97 \%$ acreditavam que toda organização empresarial deveria 
contar com um programa de qualidade de vida. A autora ressalta que as ações voltadas para a qualidade se tornaram estratégicas para o mundo dos negócios, ao mesmo tempo em que constituem investimento, visto que valorizam a vida dos funcionários e tornam 0 ambiente organizacional mais satisfatório. Considerála necessária ao ambiente organizacional também melhora o nível de desempenho.

Para Kotler (1998, p. 170), uma pessoa tem muitas necessidades em determinado momento. Algumas delas são fisiológicas, pois advêm de tensões como fome, sede, e desconforto, e outras são psicológicas, pois surgem de situações de tensão, como a necessidade por reconhecimento, estima e posse.

O estudo das necessidades e motivação é de suma importância para o entendimento da dinâmica do comportamento organizacional e das estratégias de marketing. $\mathrm{O}$ autor faz algumas adaptações das teorias de motivação humanas mais conhecidas, como as de Abraham Maslow e Frederick Herzberg, por propiciarem a análise do comportamento do consumidor e da estratégia de marketing (KOTLER, 1998, p. 170).

Entende-se satisfação como o "nível de sentimento de uma pessoa, resultante da comparação do desempenho (ou resultado) de um produto em relação às suas expectativas" (KOTLER, 1999, p. 50). O nível de satisfação está, portanto, em função da diferença entre o desempenho percebido e as expectativas, o que equivale a dizer que a satisfação ocorre quando o valor entregue ao prestador se iguala ao valor por ele esperado.
Os prestadores de serviços, em particular os do sistema prisional feminino, precisam perceber que a satisfação do cliente interno com os serviços de atendimento irá gerar satisfação, possibilitando o retorno efetivo para suas comunidades e a diminuição do índice de reincidência.

O prestador de serviço, ao se responsabilizar por seus clientes internos, institui uma fala favorável do sistema prisional feminino no qual atua, e os fatores socioeconômicos e culturais deixam de ser empecilhos para produzir serviços de qualidade, engendrando qualidade de vida para as mulheres que conquistam a liberdade.

Promover a qualidade de vida exige, então, que de um lado o sistema prisional e o clima organizacional apostem na pessoa da mulher privada de liberdade, e, de outro, que essa mulher estabeleça metas e objetivos para a sua vida, mas também desenvolva a atitude de aprender a viver bons momentos e a superar os maus em todas as demais dimensões da vida, no transcorrer de sua existência. Um dos ingredientes necessários é manter um tempo para si, para o autocuidado e autoconhecimento.

Segundo Ogata e Marchi (2007, p. 105):

(...) Isto quer dizer que a qualidade de vida não é atingida somente com grandes realizações, crescimento material ou acontecimentos fantásticos. Pequenos eventos, em casa, no trabalho ou no lazer trazem grande satisfação e ajudam a reduzir o stress. A partir disso, 
devemos nos lembrar que a qualidade de vida não é uma meta que atingimos e, pronto! Ao longo de toda a nossa vida, com momentos bons e ruins, com altos e baixos, vamos evoluindo, aprendendo e nos fortalecendo.

\section{MATERIAIS E MÉTODOS}

Após a apresentação dos objetivos do estudo e convite à participação voluntária, os sujeitos de pesquisa foram chamados a participarem e a preencherem o Termo de Consentimento Livre e Esclarecido. Realizou-se uma entrevista com seis itens voltados à delineação do perfil socioeconômico e um item voltado às condições do ambiente prisional. O sujeito contatado foi convidado, também, a preencher os itens que abrangem a Qualidade de Vida em Saúde SF-36 (CICONELLI, 1999).

A população carcerária, objeto de estudo, envolveu cento e cinquenta sujeitos do gênero feminino; desta população noventa e nove aderiram ao estudo (90\%).

Como a abordagem é quantitativa, foram utilizados os recursos disponíveis do Mini-Tab e do teste Qui-Quadrado de Aderência.

\section{Quadro 1 - Síntese das Dimensões do SF - 36}

\begin{tabular}{|c|c|}
\hline Domínios & Aspectos investigados \\
\hline 1. Capacidade Funcional & $\begin{array}{l}10 \text { itens que avaliam a presença e a extensão } \\
\text { das limitações impostas à capacidade física. }\end{array}$ \\
\hline 2. Aspectos Físicos & $\begin{array}{l}02 \text { itens que avaliam as influências desses } \\
\text { aspectos no trabalho ou em atividades } \\
\text { quotidianas. }\end{array}$ \\
\hline 3. Aspectos Emocionais & $\begin{array}{l}03 \text { itens que avaliam as influências destes } \\
\text { aspectos no trabalho ou em atividades } \\
\text { quotidianas. }\end{array}$ \\
\hline 4. Dor & $\begin{array}{l}01 \text { item que avalia as influências deste aspecto } \\
\text { no trabalho ou em atividades quotidianas. }\end{array}$ \\
\hline 5. Estado Geral de Saúde & $\begin{array}{l}05 \text { itens derivados do questionário General } \\
\text { Health Rating Index. }\end{array}$ \\
\hline 6. Vitalidade & $\begin{array}{l}04 \text { itens que consideram o nível de energia e o } \\
\text { de fadiga; a fadiga deriva do questionário } \\
\text { Mental Health Inventory. }\end{array}$ \\
\hline 7. Aspectos Sociais & $\begin{array}{l}02 \text { itens que analisam a integração social dos } \\
\text { cidadãos em atividades sociais. }\end{array}$ \\
\hline 8. Saúde mental & $\begin{array}{l}05 \text { itens que investigam as dimensões de } \\
\text { ansiedade, depressão, alteração do } \\
\text { comportamento ou descontrole emocional e } \\
\text { bem-estar psicológico. }\end{array}$ \\
\hline
\end{tabular}

O questionário SF-36 é um roteiro por trinta e seis itens englobados em oito genérico de avaliação de saúde composto escalas, que permitem investigar aspectos 
distintos, a seguir sintetizados. Cada domínio recebe um escore que varia de zero a 100 , ou seja, do pior ao melhor estado geral de saúde de cada indivíduo (MARTINEZ; PARAGUAY; LATORRE, 2004). As questões são transformadas em oito domínios e cada um deles recebe um valor final, denominado Raw Scale, que não apresenta nenhuma unidade de medida.

\section{RESULTADOS}

Apresentam-se os resultados obtidos a partir da aplicação, no segundo semestre de 2010, do Questionário SF-36, a 99 mulheres encarceradas. Os valores médios obtidos, utilizando os recursos do Mini-TAB, em cada domínio foram:

\section{Quadro 2 - Descriptive Statistics}

\begin{tabular}{lccccccc}
\hline \multicolumn{1}{c}{ Domínio } & $\mathbf{N}$ & Média & $\begin{array}{c}\text { Desvio } \\
\text { Padrão }\end{array}$ & $\begin{array}{c}\text { CoefVar } \\
(\%)\end{array}$ & Mínimo & Mediana & Máximo \\
\hline $\begin{array}{l}\text { Capacidade } \\
\text { Funcional }\end{array}$ & 99 & 26.230 & 4.338 & 16.73 & 14.000 & 28.000 & 31.000 \\
$\begin{array}{l}\text { Aspectos } \\
\text { Físicos }\end{array}$ & 99 & 6.667 & 1.714 & 25.71 & 1.000 & 7.000 & 9.000 \\
$\begin{array}{l}\text { Estado Geral } \\
\text { Saúde }\end{array}$ & 99 & 21.923 & 4.835 & 22.06 & 8.000 & 22.200 & 32.800 \\
$\begin{array}{l}\text { Saúde Mental } \\
\text { Aspectos }\end{array}$ & 99 & 8.848 & 2.723 & 30.78 & 1.000 & 10.000 & 12.000 \\
$\begin{array}{l}\text { Emocionais } \\
\text { Aspectos }\end{array}$ & 99 & 4.505 & 1.402 & 31.13 & 1.000 & 5.000 & 6.000 \\
$\begin{array}{l}\text { Sociais } \\
\text { Vitalidade }\end{array}$ & 99 & 10.051 & 2.149 & 21.39 & 5.000 & 10.000 & 14.000 \\
Dor & 99 & 25.172 & 5.664 & 22.50 & 10.000 & 26.000 & 35.000 \\
\hline
\end{tabular}


Boxplot of CAPFUN, ASPFIS, EGS, SaudMent

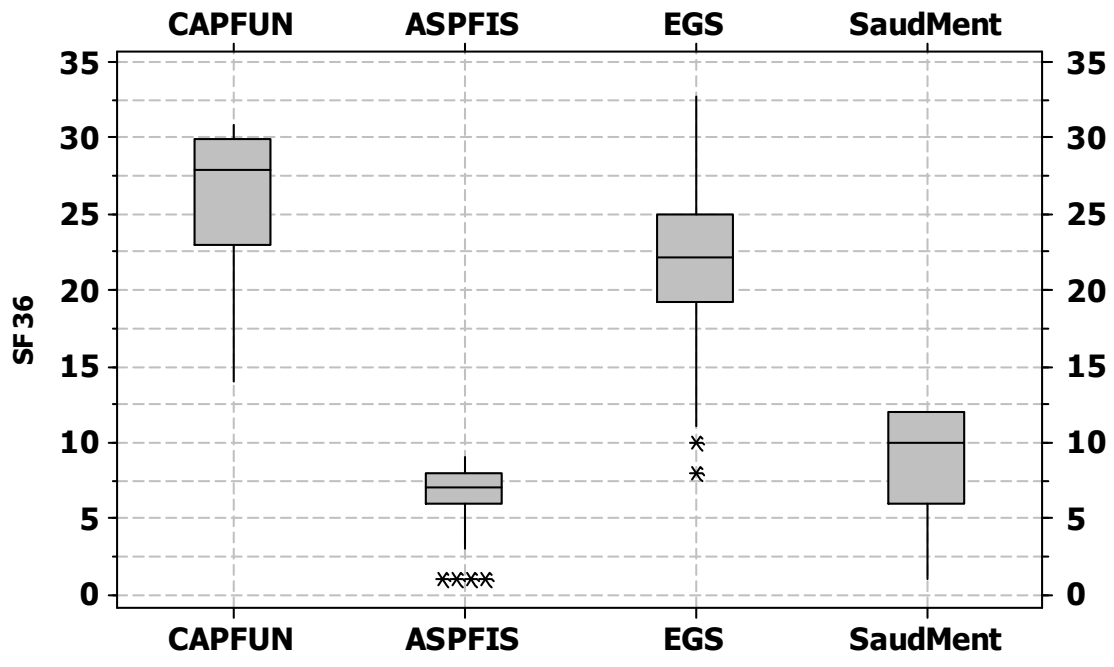

Fig. 1 - Boxplot.

Boxplot of ASPEMOC, ASPSOC, VITA, DOR

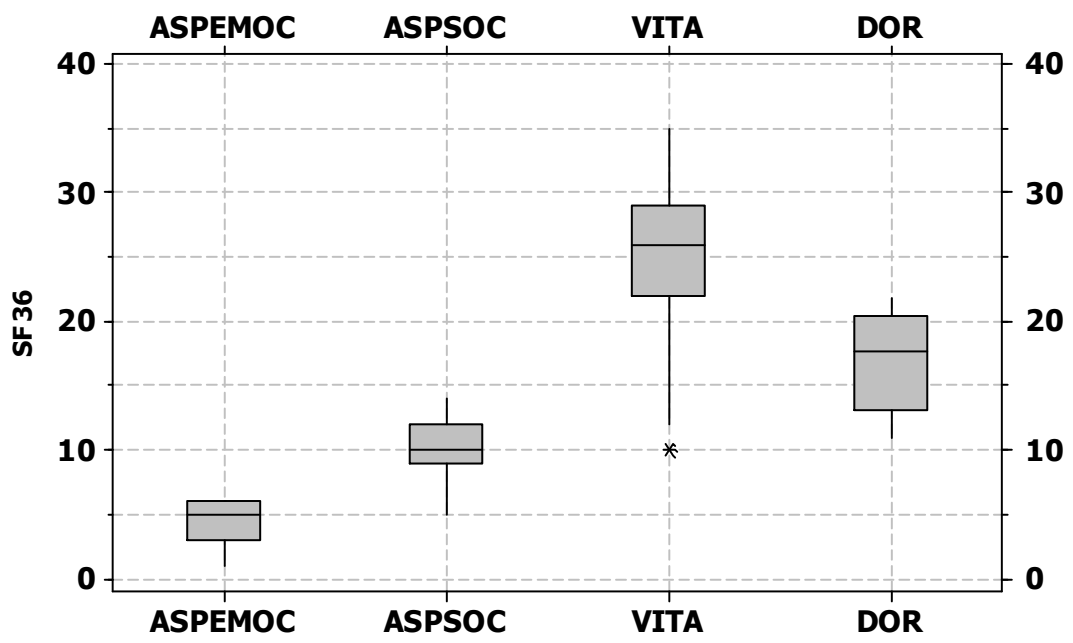

Fig. 2 - Boxplot. 


\section{Quadro 3 - Correlação entre os domínios}

\begin{tabular}{|c|c|c|c|c|c|c|}
\hline Dimensões & $\begin{array}{c}\text { Aspectos } \\
\text { Físicos } \\
\text { R / P }\end{array}$ & $\begin{array}{c}\text { Saúde } \\
\text { Mental } \\
\text { R / P }\end{array}$ & $\begin{array}{c}\text { Aspectos } \\
\text { Emocionais } \\
\text { R / P }\end{array}$ & $\begin{array}{c}\text { Aspectos } \\
\text { Sociais } \\
\text { R / P }\end{array}$ & 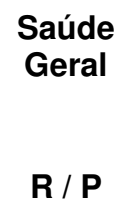 & $\mathbf{R} / \mathbf{P}$ \\
\hline Capacidade Funcional & $\begin{array}{c}0.285 \\
(0.004)^{*}\end{array}$ & $\begin{array}{c}-0.283 \\
(0.004)^{*}\end{array}$ & $\begin{array}{c}0.068 \\
(0.506)\end{array}$ & $\begin{array}{l}-0.064 \\
(0.531)\end{array}$ & $\begin{array}{l}-0.036 \\
(0.720)\end{array}$ & $\begin{array}{l}-0.3331 \\
(0.001)^{*}\end{array}$ \\
\hline Aspectos Físicos & -------- & $\begin{array}{c}0.085 \\
(0.401)\end{array}$ & $\begin{array}{c}0.381 \\
(0.001)^{\star}\end{array}$ & $\begin{array}{c}0.113 \\
(0.267)\end{array}$ & $\begin{array}{c}0.144 \\
(0.155)\end{array}$ & $\begin{array}{c}-0.224 \\
(0.026)^{*}\end{array}$ \\
\hline Saúde Mental & ---------- & ----------- & $\begin{array}{c}0.052 \\
(0.607)\end{array}$ & $\begin{array}{c}0.062 \\
(0.540)\end{array}$ & $\begin{array}{c}0.148 \\
(0.144)\end{array}$ & $\begin{array}{c}0.102 \\
(0.315)\end{array}$ \\
\hline Aspectos Emocionais & ----------- & ----------- & ----------- & $\begin{array}{c}0.015 \\
(0.882)\end{array}$ & $\begin{array}{c}0.135 \\
(0.182)\end{array}$ & $\begin{array}{c}-0.204 \\
(0.043)^{*}\end{array}$ \\
\hline Aspectos Sociais & ----------- & ----------- & ----------- & ----------- & $\begin{array}{c}0.095 \\
(0.349)\end{array}$ & $\begin{array}{c}0.123 \\
(0.225)\end{array}$ \\
\hline Saúde Geral & ----------- & ---------- & ----------- & ----------- & --------- & $\begin{array}{c}0.037 \\
(0.714)\end{array}$ \\
\hline
\end{tabular}

Nota 1 - Pearson Correlation (P-Value).

Legenda:

Correlação

Interpretação

$r=0.00$

Não há relacionamento entre $\mathrm{x}$ e $\mathrm{y}$

$r=0.40$

Baixo relacionamento entre $x \mathrm{e} y$

$r=0.70$

Moderado relacionamento entre $x$ e $y$

$r>0.8$ até 1.00

Alto relacionamento entre $x$ e y. Perfeita correspondência entre $x$ e $y$.

\section{DISCUSSÃO}

Entende-se capacidade funcional (CF) como a ausência de dificuldades no desempenho de certos gestos e de certas atividades da vida cotidiana. Os conceitos fazem parte de um sistema de Classificação Internacional de Comprometimento, Incapacidades e Desvantagens (ICIDH) da World Hearth Organization (WHO).

O comprometimento se relaciona aos aspectos orgânicos: é a perda ou alteração das estruturas ou funções sejam elas psicológicas ou fisiológicas. A definição operacional de capacidade funcional está relacionada ao grau de preservação da capacidade de o indivíduo realizar atividades da vida diária (AVDs) e à capacidade para desempenhar as atividades instrumentais da vida diária (AIVDs).

Em se tratando do conjunto de mulheres participantes deste estudo ( $\mathrm{N}=99$ ), o valor alcançado na dimensão Capacidade Funcional, numa escala de zero a 100 , foi de 26,23. Esse resultado indica que as AVDs 
referentes ao autocuidado das mulheres encarceradas destacam a dificuldade em cuidar-se e responder por si só no espaço prisional limitado, denunciando dificuldade de locomoção, de tomar banho, de vestir-se e de usar o banheiro com privacidade.

Esse índice demonstra que as AIVDs relacionadas com funções mais complexas, que permitem a vida independente na comunidade, como fazer compras, cozinhar, arrumar a casa, telefonar, usar o transporte, lavar roupa, tomar remédio e ter habilidade para lidar com as próprias finanças, não se realizam.

O índice demonstra, ainda, que as Atividades Avançadas de Vida Diária (AAVDs), como dirigir carro, praticar esporte, andar de bicicleta, cantar, viajar, dançar, entre outras, também são igualmente prejudicadas. Embora não sejam fundamentais para uma vida independente, tendem a ser dependentes de vontade e de motivação, portanto sua presença é indicativa de maior capacidade funcional e melhor saúde física e mental.

O déficit em capacidades funcionais reflete a dependência funcional desse conjunto de mulheres, uma vez que leva à dificuldade em locomoção, déficits sensoriais e descontinuidade do funcionamento intelectual e afetivo. As mulheres em regime prisional poderiam ser capazes de ativar mecanismos de compensação e otimização para enfrentar perdas em funcionalidade, lançando mão de recursos tecnológicos, solicitando apoio social e psicológico, ou valendo-se do controle exercido sobre o comportamento de outras pessoas, mas a hostilidade do sistema carcerário não lhes permite o estabelecimento de tais processos.
Quando em situação de liberdade provisória ou permanente, essas incapacidades resultam no comprometimento para realizar atividades rotineiras, o que gera desvantagens tanto nas relações familiares quanto no mundo do trabalho. Esse é o prejuízo social resultante do comprometimento e da incapacidade.

Os índices baixos relativos aos aspectos físicos (6.667) e emocionais (4.505) tendem a diminuir a capacidade funcional dessas mulheres. Essa dimensão é influenciada pela saúde mental, aspectos sociais, saúde geral e dor. Esses índices permitem uma reflexão em relação ao espaço prisional sob o olhar da ergonomia.

O sistema prisional, estruturado e organizado para o gênero masculino, não deu conta de atender às necessidades do homem, e, quando necessário, foi adaptado para o gênero feminino sem que as questões de inadequação anteriores tivessem sido resolvidas. Além disso, as adequações não deram conta das necessidades específicas das mulheres. Percebe-se, assim, que aspectos relativos à ergonomia não foram considerados nesse processo.

Esse tipo de preocupação é que pode favorecer 0 bom desenvolvimento das atividades funcionais e a manutenção da capacidade funcional e dos aspectos físicos. A preocupação com a qualidade de vida no Sistema Prisional deve partir dos gestores, que precisam acreditar que a qualidade de vida está diretamente relacionada à qualidade do sistema, o que significa uma atenção à integridade física e mental, bem como à saúde da detenta. (BISPO, 2009).

Os aspectos físicos (6.667) são 
abalados pelos aspectos emocionais (4.505), sociais (10.051), de saúde mental (8.848) e saúde geral (21.923), e influenciam a camuflagem do índice relativo à dor (6.667).

A definição de saúde possui implicações legais, sociais e econômicas dos estados de saúde e doença; sem dúvida, a definição mais difundida é a encontrada no preâmbulo da Constituição da Organização Mundial da Saúde: "saúde é um estado de completo bem-estar físico, mental e social, e não apenas a ausência de doenças".

Em 1981, Leon Kass questionou se o bem-estar mental seria parte do campo da saúde, e definiu-a como: "o bem-funcionar de um organismo como um todo", ou ainda "uma atividade do organismo vivo de acordo com suas excelências específicas." Lennart Nordenfelt, por sua vez, definiu-a, em 2001, como um estado físico e mental em que é possível alcançar todas as metas vitais, dadas as circunstâncias.

Cada definição tem seu mérito, mas a do Escritório Regional Europeu/OMS, apresentada no relatório "Prisões e de Saúde", pode ser mais facilmente operacionalizada para uso em estudos com grupos particulares, como é o conjunto de mulheres encarceradas:

À medida que um indivíduo ou grupo é capaz, por um lado, de realizar aspirações e satisfazer necessidades e, por outro, de lidar com o meio ambiente, a saúde é vista como um recurso para a vida diária, não o objetivo dela; abrange os recursos sociais e pessoais, bem como as capacidades físicas. É um conceito positivo (ESCRITÓRIO REGIONAL EUROPEU. OMS, 2002).

Durante a revisão de literatura não foram encontradas informações sobre o bom estado geral de saúde da população carcerária, masculina ou feminina, o que se encontra nega a preocupação com o bem-estar de saúde. As adaptações são feitas apenas para garantia e aumento do controle social: pouco tem sido proposto e realizado para a garantia do estado de saúde.

O índice 21.923, relativo ao aspecto Estado Geral de Saúde, revela que a população participante deste estudo tem uma saúde precária, ao relacioná-la aos seguintes fatores/aspectos:

1. capacidade funcional: o estado geral de saúde rebate na diminuição da eficiência e eficácia nas atividades desempenhadas;

2. aspectos sociais (índice de 10.051): pode-se inferir que é o responsável pela diminuição das oportunidades de índices melhores no estado geral de saúde; e

3. baixos índices nos aspectos físicos (6.667), emocionais (4.505) e na saúde mental (8.484) se refletem na saúde geral.

Diante dessas constatações, não se poderia esperar melhor índice referente ao estado geral de saúde das mulheres aprisionadas. Em razão desses agravos da saúde da população observada é imprescindível que os gestores definam ações voltadas ao Estado Geral de Saúde, que tornem essas mulheres protagonistas de suas vidas quando da liberdade 
provisória ou liberdade definitiva (CAMPOS; BARROS; CASTRO, 2004).

Saúde Mental é o equilíbrio emocional entre o patrimônio interno e as exigências ou vivências externas, propiciando capacidade de administrar a própria vida e as suas emoções dentro de um amplo conjunto de variações, sem perder o valor do real e do precioso. É ser sujeito de suas próprias ações sem perder a noção de tempo e espaço, buscando viver a vida em sua plenitude, respeitando o legal e o outro.

Como o aspecto de Saúde Mental se mostrou baixo, é possível afirmar que as mulheres têm dificuldades em estar de bem consigo e com os outros; de aceitar as exigências da vida; saber lidar com as boas emoções e também com as desagradáveis; reconhecer seus limites e buscar ajuda quando necessário.

A gestão deve se comprometer em favorecer ações que propiciem às detentas desenvolverem atitudes positivas em relação a si próprias; crescimento, desenvolvimento e autorrealização; integração e resposta emocional; autonomia e autodeterminação; percepção apurada da realidade; domínio ambiental e competência social, pois são esses aspectos que favorecem melhoria na saúde mental.

Em relação à influência dos fatores sociais na saúde mental das mulheres participantes deste estudo, a percepção e a consciência prejudicadas as predispõem a vivenciarem dificuldades pessoais e/ou coletiva em solucionar questões da vida cotidiana, modificá-las e de intervir sobre elas (URIBE VASCO et al., 1994).

Em nível laboral, as condições do Sistema Prisional não têm contribuído para que as detentas ocupem postos de trabalho no futuro, em liberdade; que tenham o controle necessário às atividades ocupacionais e se encontrem adequadas às exigências do cargo.

A Saúde Mental vincula-se aos fatores psicossociais de risco, compreendidos como uma variedade de fatores psicológicos e sociais. (BINIK, 1985). Não existe termo mais apropriado para descrever as características da pessoa: traços de personalidade, mecanismos de defesa, estados emocionais e cognitivos, e as condições socioambientais.

As mulheres, por estarem aprisionadas, revelam que experiências anteriores favoreceram o comprometimento da sua saúde mental, que somado à experiência de detenção aumentaram as oportunidades de riscos em relação à vulnerabilidade ao estresse, à não satisfação, à fadiga crônica, à ansiedade, ao neuroticismo, à extroversão, ao autoconceito e à baixa estima.

Esses fatores psicossociais podem vir acompanhados de um desconforto emocional significativo e podem aumentar a probabilidade de as detentas desenvolverem problemas de comportamento, 0 que justificaria o baixo índice da Dimensão Saúde Mental (8.848).

Não se pode, contudo, desconsiderar a vertente biológica, dado que a susceptibilidade da pessoa, quer genética, quer adquirida, é considerada de extrema importância para a saúde mental. Isso porque os fatores psicossociais podem interagir com a dimensão biológica e contribuir para o desenvolvimento de comportamentos inadequados. 
O índice de 8.848 , relativo à Saúde Mental, revela uma possível relação com o de Capacidade Funcional (26.230) e de Estado Geral de Saúde (21.923). O baixo índice da Capacidade Funcional propicia dependências nas AVD's e AIVD's, colaborando com ocorrências de dependência mental manifestas por quadros de depressão e demência, ocasionando perdas de independência e autonomia (GORDILHO et al., 2001). Essa dimensão influencia os aspectos emocionais (4.505), sociais (10.051), de saúde geral (21.923) e dor (6.667).

A gestão do sistema poderia usar os indicadores revelados por este estudo para identificar aquelas mulheres com alto risco de perda funcional e orientar ações para a sustentação da funcionalidade, mantendo-as na comunidade, quando libertas, com o máximo de independência e qualidade de vida.

Entende-se o aspecto emocional como a parte do ser que contém a programação que cria os sentimentos expressos por meio do corpo físico: é maneira como o corpo responde continuamente às alterações emocionais, tanto positivas quanto negativas. Quando negativa ocorre em episódios repetidos ou durante longos períodos, como, por exemplo, estresse emocional e ansiedade crônica, o corpo pode se ressentir.

O índice de 4.505, referente ao aspecto emocional, demonstra que as presidiárias vivenciaram e vivenciam emoções negativas durante episódios repetitivos e/ou por longos períodos, levando seus corpos físicos a um estado de estagnação, perdendo sua capacidade de adaptação a diferentes estímulos, e, com isso, o surgimento de doenças psicossomáticas torna-se muito mais propício (LEDERMAN, 2001).

$\mathrm{O}$ baixo índice relativo às emoções deve ter contribuído com os baixos índices de saúde mental, capacidade funcional, estado geral de saúde e vitalidade. Essas questões vão se apresentar na perda da capacidade de adaptação das detentas à sociedade civil, quando em liberdade ou liberdade provisória.

Essa dimensão interfere no aspecto social (10.051) e no estado de saúde geral, (21.923) e auxilia na não manifestação da dor, em razão do amortecimento da estrutura afetiva. Supõe-se que essas mulheres já vieram de um ambiente pouco acolhedor e protetor, passaram a viver num sistema de elevado controle social, sem, contudo, contar com programas e ações voltados para vivências de reestruturação psicossocial que favorecessem a manutenção da saúde mental, do estado geral de saúde, vitalidade, capacidade funcional e, sobretudo, qualificação profissional.

A ausência de um ambiente acolhedor e protetor, em que a experiência é vivenciada, e a não cicatrização de feridas do passado não permitirão que a mulher aprisionada, quando em liberdade, venha atravessar com segurança eventuais momentos de medo, dor, tristeza e raiva, facilitando a reincidência.

Ao contrário, se a gestão do sistema prisional gerar programas de apoio às necessidades das detentas, as partes obscuras da personalidade serão superadas, levando a uma compreensão clara da própria vida. Como resultado, a 
mulher se apropriará de sentimentos e emoções adormecidos, como alegria e criatividade (BENSON; STARK, 1998).

$\mathrm{Na}$ situação de encarceramento, os aspectos sociais se voltam para as relações de poder do sistema carcerário e do poder exercido pelas demais detentas, mesmo sendo oficialmente um grupo de iguais. Já nas relações com o ambiente externo, as detentas são consideradas excluídas socialmente e o seu retorno como cidadãs não significa sua inclusão social. As normas carcerárias definem o conjunto de relações sociais a serem estabelecidas pelas mulheres, em relação a elas e delas em relação ao sistema. Os contatos sociais sendo vigiados e controlados, sejam eles com os de dentro ou com os de fora, permitem inferir que o índice de qualidade de vida em saúde seja insatisfatório.

Os aspectos sociais (10.051) inibidos não favorecem a sociabilidade entre elas, nem as interações criativas e inovadoras dificultam a vida harmônica no espaço prisional, a resolução de problemas pessoais e a elaboração de um projeto de vida futuro. Este índice não favorece que a sociabilidade no contexto onde se encontram leve à construção de coping positivo, privilegiando as ocorrências de coping negativo no enfrentamento das diversas situações, como pequenas rusgas, competição, e atos violentos.

O coping se define enquanto "esforços cognitivos e comportamentais para responder às exigências específicas, internas e/ou externas, que são avaliadas como excedendo os/ou estando nos limites dos recursos do indivíduo" (FOLKMAN; LAZARUS, 1988, p. 2).
Embora este estudo não tenha avaliado as estratégias de enfrentamento das mulheres, a qualidade de vida em saúde foi indicada como insatisfatória, particularmente nas dimensões saúde mental, aspecto social e aspecto emocional. Essas dimensões, somadas às manifestações comportamentais, cognitivas e afetivas, durante as atividades desenvolvidas pelo Instituto Casa da Mulher, permitem afirmar que as mulheres fazem uso de estratégias de enfrentamento negativas às situações vividas.

Como a lógica capitalista se insere na dinâmica de toda e qualquer organização social, no sistema prisional as relações de poder e de domínio também se manifestam por duas vias: a do sistema e a das mulheres encarceradas. Diante desse cenário ocorre a segregação da sociabilidade, que traz alguns fatores que podem contribuir para 0 aumento da violência e da criminalidade entre as internas.

Pela perspectiva da sociedade civil as detentas se encontram excluídas, não apenas pelo aspecto econômico-financeiro. Esse foco esconde um viés político e ético, uma vez que a exclusão deve ser vista pela necessidade da inclusão social.

Em que pese existir ainda deficiências no sistema prisional brasileiro, as ações positivas são o reconhecimento, por parte do Estado, da existência de diferenças culturais, sociais, econômicas, e físicas, entre outras, que necessitam da atuação do próprio Estado no sentido de buscar mitigar a situação excludente.

Entende-se a vitalidade como a sintonia de ser integral. A essência é ser 
vital, ser feliz, ter leveza e equilíbrio. Nesse sentido, ter vitalidade é possuir a energia de ser integral. Em outras palavras, somos um ser destinado à perfeição, alcançada por meio de experiências evolutivas. Esse ser é o ser principal, o ser pensante, o comandante do corpo, e nele, o ser principal, estão as qualidades morais e intelectuais do ser integral.

Os espaços institucionais destinados ao encarceramento não permitem movimento corporal satisfatório, que leve ao desenvolvimento de atividades na vida cotidiana, diminuindo, portanto, a vitalidade. Esta dimensãose apresentou com índice 25.172, considerado insatisfatório. Outros fatores, como vigor físico (6.667) e saúde mental (8.848), também insatisfatórios, contribuem para que a condição vital das detentas fique a desejar.

A vitalidade não é tão simples de ser recuperada na futura vida em liberdade, uma vez que demanda bons níveis de energia, qualidade das atividades sociais e melhoria em todas as dimensões definidas pelo SF36, que não foram possíveis de serem trabalhadas na vida prisional e não são facilmente passíveis de serem trabalhadas dentro de um sistema social excludente.

Em geral associa-se essa dimensão apenas a um fenômeno neurofisiológico, mas é muito mais que isso, pois existem componentes psíquicos, sociais e culturais na forma como se sente e se expressa a dor. Não basta, portanto, dar alívio para os males do corpo. É necessário avançar de uma supervalorização da dimensão biológica humana para a valorização das dimensões psicoemocional e social (SARTI, 2001).
Com respeito a essa dimensão, o índice de 6.667 é considerado elevado em relação às condições vividas por esse conjunto de mulheres, o que se contrapõe aos valores da cultura brasileira, que permite às mulheres explicitar a dor e o sofrimento.

$\mathrm{Na}$ situação histórica em que se encontram, as detentas são levadas a suportar a dor em silêncio, em sinal de virilidade, o que justifica os índices de capacidade funcional (26.230) de vitalidade (25.172) e do estado de saúde geral (21.923).

O índice de 6.667 , relativo à dimensão da dor, embora se apresente como irrelevante, revela que a qualidade de vida em saúde dessas mulheres é insatisfatória, uma vez que são baixos os índices relativos à saúde mental (8.848), aos aspectos físicos (6.667), aos aspectos emocionais (4.505) e à capacidade funcional.

A correlação entre capacidade funcional e aspectos físicos $\left(r=0.285^{\star}\right)$; e entre os aspectos físicos e aspectos emocionais $\left(r=0.381^{*}\right)$ é positiva e fraca, mas de significância estatística.

A correlação positiva e fraca e sem significância estatística foi encontrada entre: capacidade funcional e aspectos emocionais $(r=0.68)$; aspectos físicos e saúde mental $(r=0.085)$; aspectos físicos e aspectos sociais $(r=0.113)$; aspectos físicos e saúde geral $(r=0.144)$; saúde mental e aspectos emocionais $(r=0.052)$; saúde mental e aspectos sociais ( $r=0.062)$; saúde mental e estado de saúde geral ( $r=0.148)$; saúde mental e dor $(r=0.102)$; aspectos emocionais e aspectos sociais $(r=0.015)$; aspectos emocionais e estado de saúde geral $(r=0.135)$; aspectos sociais e estado geral de 
saúde ( $r=0.095)$; aspectos sociais e dor $(r=0.123)$ e estado geral de saúde e dor $(r=0.037)$.

A correlação negativa e fraca, com significância estatística, foi encontrada entre: capacidade funcional e saúde mental $\left(r=-0.283^{*}\right)$; capacidade funcional e dor $\left(r=-0.3331^{*}\right)$; aspectos físicos e dor $\left(r=-0.224^{*}\right)$ e aspectos emocionais e dor $\left(r=-0.204^{\star}\right)$.

A correlação negativa e fraca, sem significância estatística foi encontrada entre: capacidade funcional e saúde geral $(r=-0.036)$ e capacidade funcional e dor $(r=-0.224)$.

\section{CONSIDERAÇÕES FINAIS}

A melhoria da qualidade de vida em saúde das mulheres presidiárias merece atenção, pois num futuro, quando em liberdade, terão que buscar inserção no mercado de trabalho e nas relações sociais em geral.

Tratar da saúde das mulheres detentas constitui área da Saúde Pública, que objetiva intervir nas relações sociais e de trabalho. Dessa forma, essas mulheres demandam proteção à sua saúde, desenvolvida por meio de ações de vigilância dos riscos no ambiente prisional e também no mundo do trabalho (BRASIL, 2001).

Os condicionantes sociais, econômicos, tecnológicos e organizacionais responsáveis pela inserção social, os fatores de riscos e os decorrentes da organização de trabalho, presentes na sociedade civil, são vitais para a qualidade de vida das mulheres em regime prisional.
A consideração pela qualidade de vida em saúde dos cidadãos em geral ainda não é a tônica na maioria das organizações sociais, mas aquelas que passaram a focalizar o seu usuário começam a adotar mudanças nos processos de atendimento, contemplando as relações de saúde em toda a sua complexidade, por meio de uma atuação interdisciplinar e intersetorial de abordagens metodológicas.

Esse cenário configura, portanto, situações que exigem mais pesquisas e conhecimento para que se possam traçar propostas coerentes e efetivas de intervenção junto ao sistema prisional brasileiro.

Considerados os escores relativos às diferentes dimensões, pode-se afirmar que as participantes deste estudo não estão interagindo bem com a sua individualidade nem com o mundo externo, seja por meio das atividades sociais ou do trabalho. O escore obtido em saúde mental (8.848) permite afirmar que essas participantes não interagem com suas subjetividades.

Os resultados possibilitam concluir que o conjunto de detentas não equilibra suas forças internas com as externas, manifestando, por avaliação subjetiva, má qualidade de vida em saúde.

Esse aspecto pode não ser de responsabilidade direta do sistema prisional, pois é muito mais abrangente, incluindo entre outras áreas, a educação, a moradia, o lazer e demais atividades sociais. É certo, porém, que no ambiente prisional é necessário propiciar satisfação, para manter uma relação direta (MENDES; LEITE, 2004) com a qualidade de vida.

Conclui-se que a qualidade de vida em 
saúde das noventa e nove detentas é insatisfatória, mas não há como avaliar se a sua autopercepção de saúde evidencia essa realidade.

É lamentável concluir que essas mulheres são reféns não apenas dos atos ilegais cometidos, mas também das encruzilhadas que permeiam o sistema social e não permitem a autopercepção de si mesmas e do social, o que impossibilita um transcender de si próprias e da realidade social.

\section{REFERÊNCIAS}

ALMEIDA, I. M. de. Trajetória da análise de acidentes: o paradigma tradicional e os primórdios da ampliação da análise. Revista Árvore, Viçosa, v. 10, n. 19, p. 185-202, 2006.

AGUIAR, M F. Lazer e Produtividade no Trabalho: Turismo em análise. São Paulo, v.1, n. 2, p. 111-124, nov, 2000.

BINIK, Y. M. Psychosocial Predictors of Sudden Death: A Review and Critique. Soc, Sci, Med., v.20, n.7, p.667-680, 1985.

BISPO, P. A saúde das pessoas afeta as empresas. 2009. RH.com.br. Disponível em: $<$ http://www.rh.com.br/Portal/Qualidade_de_ Vida/Entrevista/5057/a-saude-das-pessoasafeta-as-empresas.html>. Acesso em: 04 dez. 2010.

BOORSE C. Health as a theoretical concept. Philosophy of Science, v.44, p.542-473, 1977.

BRITO, T. P. Análise ergonômica do trabalho em uma empresa beneficiadora de acrílicos na região de Joinville-SC, 2009. Disponível em:

http://www.ergonomianotrabalho.com.br/anal ise-ergonomica-empresa-beneficiadora-deacrilicos.pdf>. Acesso em: 04 dez. 2010.

BUSS, P. M. Promoção da saúde e qualidade de vida. Ciênc. saúde coletiva, Rio de Janeiro, v. 5, n. 1, 2000. Disponível em: $<$ <ttp://www.scielo.br/scielo.php?script=sci_a rttext\&pid=S1413-

$81232000000100014 \& \operatorname{lng}=e n \& n r m=i s o>$.

Acesso em: 04 ago. 2011. http://dx.doi.org/10.1590/S1413-

81232000000100013

BIFF, P. Avaliação da Capacidade funcional e Prevalência de Sintomas Osteomusculares em Trabalhadores de uma Indústria de Materiais Elétricos de Caxias do Sul, RS. 2006. Dissertação (Mestrado em Saúde Coletiva). Universidade Vale dos Sinos, São Leopoldo, 2006.

BRAMANTE, C. M. Resolução das Dores Pulpares. Atualização na Clínica Odontológica. Porto alegre: Artes Médicas, 1996. p. 201-210.

CAMPOS, G. W.; BARROS, R. B.; CASTRO, A. M. Avaliação de política nacional de promoção à saúde. Revista Ciência e saúde coletiva, Rio de Janeiro, v. 9, n. 3, p. 745749, 2004.

COUTO, H. A. Como implantar a ergonomia na empresa. Belo Horizonte: Ergo, 2002.

CICONELLI, R. M. et al. Tradução para a língua portuguesa e validação do questionário genérico de qualidade de vida SF - 37 (Brasil SF - 36). Revista Brasileira de Reumatologia, São Paulo, v. 39, n. 3, p. 143-157, maio-jun. 1999.

DAVIS, K.; NEWSTRON, J. W. Comportamento humano no trabalho. São Paulo: Pioneira Thompson Learning, 2001. v. 1. $207 \mathrm{p}$. 
DANIELLOU, F. A ergonomia em busca de seus princípios: debates epistemológicos. 1. ed. São Paulo: Edgard Blücher, 2004.

DEJOURS, C. A loucura do trabalho: estudo de psicopatologia do trabalho. 5. ed. São Paulo: Cortez, 2003.

DRUCKER, P. F. Tecnologia, Gerência e Sociedade. Petrópolis: Vozes. 2. ed. 1973.

ESCRITÓRIO REGIONAL EUROPEU. OMS

Relatório Prisões e de Saúde. 2002. Disponível em: http://www.euro.who.int. Acesso em: 09 ago. 2011.

ESPARBES, S.; SORDES ADER, F.; TAP, P. Présentation de l'échelle de enfrentamento. Em Actes de las Jour du Nees et Laboratoire Personnalisation Changements Sociaux São CRIQ: Université de Toulouse - Le Mirail, 1993. p. 89-107.

FARIA, N. M. Organização do Trabalho. São Paulo: Atlas, 1998. 243 p.

FERNANDES, E. C. Qualidade de Vida no Trabalho: como medir para melhorar? Salvador: Casa da Qualidade, 1996.

GARVIN, D. A. Gerenciando a Qualidade. Rio de Janeiro: Qualitymark, 1992.

GIMENEZ, P. P. Atuação Preventiva na Saúde do Trabalhador. Rev. Fisioterapia, v. 5, n. 44 , p. 8-10, 2004

GIANESI, I. G. N.; CÔRREA, H. L. Administração Estratégica de Serviços. São Paulo: Atlas, 1996.

GONÇALVES, J. E. L. Os impactos das novas tecnologias nas empresas prestadoras de serviços. Revista de Administração de Empresas, São Paulo, v. 4, n.1, p. 63-81, jan./fev., 1994.

GORDILHO, A. et al. Desafios a serem enfrentados no terceiro milênio pelo setor saúde na atenção integral ao idoso. Rio de Janeiro: UnATI/UERJ, 2000. 90p.

JURAN, J. Juran's Quality control handbook. 4. ed. New York: Juran's Quality control, 1988.

KASS, L. Mudança e Permanência: reflexões sobre o contrato social, ética da ciência no interesse público. In Vitro, v. 17, p.1091-1099, 1981.

KOTLER, P. Administração de marketing. 5. ed. São Paulo: Atlas, 1998.

KOTLER, P. Marketing para o Século XXI: como criar, conquistar e dominar mercados? São Paulo: Futura, 1999.

LEDERMAN, E. Fundamentos da Terapia Manual: Fisiologia, Neurologia e Psicologia. São Paulo: Manole, 2001.

LIMONGI, S. C. O. Fonoaudiologia: informação para a formação: procedimentos terapêuticos em linguagem. São Paulo: Guanabara, 2003. cap. 5, p. 67-90.

LOPES, A. D.; CICONELLI, R. M.; REIS, F. B. dos. Medidas de Avaliação de Qualidade de Vida e de ESTADOS Saúde em ortopedia. Rev. bras. ortop., São Paulo, v. 42, n. 11-12, dez. 2007.

OGATA, A.; MARCHI, R. Wellness? Seu Guia de Bem-Estar e Qualidade de Vida. 2. ed. Campus-Elsevier, 2007, 152 p.

MARCHETTI, R.; PRADO, H. M. Um tour pelas medidas de satisfação do consumidor. Revista de Administração de Empresas, v. 41, n. 4, p. 56-67, out.-dez., 2001.

MARTINEZ, M. C.; PARAGUAY, A. I. B. B.; LATORRE, M. do R. D. de O. Relação entre satisfação com aspectos psicossociais e saúde dos trabalhadores. Rev. Saúde Pública, v. 38, n. 1, p. 55-61, 2004. 
MANZIERE, D. S. et al. Estudo dos Efeitos do Liang Gong em 18 Terapias na Qualidade de Vida dos Trabalhadores de uma Empresa Siderúrgica do Município de São Paulo. Fisiobrasil, v. 10, jul.-ago., 2006.

MENDES, R. A.; LEITE, N. Ginástica Laboral: princípios e aplicações práticas. São Paulo: Manolo, 2004.

MINAYO, M. C. de S.; HARTZ, Z. M. de A.; BUSS, P. M. Qualidade de Vida e Saúde: um debate necessário. Rio de Janeiro. Revista Ciências e Saúde Coletiva, n. 5, n. 1, 2000. Disponível em: $<$ http://www.scielo.br/scielo.php?script=sci_a rttext\&pid=S1413-

$81232000000100002 \& \operatorname{lng}=e n \& n r m=i s o>$.

Acesso em: 09 ago. 2011.

MORAES, S. P. de. (Coord.). Relatório final da Conferência Regional de Direitos Humanos. Instituto Pró-Cidadania. Observatório de Direitos Humanos. 2008. Disponível em: www.institutoprocidadania.org.br. Acesso em: 09 ago. 2011.

NORDENFELT, L. On the goals if medicine, health enlhancement aond social welfare. Heatlh Care Anal., v. 9, n.1, p. 15-23, 2001.

REMEN, R N. O Paciente como Ser Humano. São Paulo: Summus, 1993.

ROGERS, M. Os Clientes Valiosos. HSM Management. n. 9, p. 136-140, jul.-ago. 1998.

RODRIGUES, R. N.; ALVES, L. C. Determinantes da autopercepção de saúde entre idosos do Município de São Paulo, Brasil. Revista Panamericana de Saúde Pública, v. 17, n. 5, p. 333-341, 2005.

SARTI, C. A. A dor, o indivíduo e a cultura. Saúde e Sociedade, v. 10, n. 1, p. 3-13. 2001.
SARTI, C. A. O reconhecimento do outro: uma busca de diálogo entre Ciências Humanas e Ciências da Saúde. Tese (livre docência) Universidade Federal de são Paulo, São Paulo, 2003.

SEILD; ZANNON. Qualidade de Vida e Saúde: aspectos conceituais e metodológicos. Cadernos de Saúde Pública, Rio de Janeiro, v. 20, n. 2, p. 580-588, 2004. Disponível em: $<$ http://www.scielo.br/scielo.php?script=sci_a rttext\&pid=S0102-

$311 X 2004000200027 \& \operatorname{lng}=e n \& n r m=i s o>$.

Acesso em: 09 ago. 2011.

SORJ, B. Sociologia e trabalho: Mutações, Encontros e desencontros. Rev. bras. Ci. Soc., São Paulo, v. 15, n. 43, Junho de $2000 . \quad$ Disponível em $<$ http://www.scielo.br/scielo.php?script=sci_a rttext\&pid=S0102-

$69092000000200002 \& \operatorname{lng}=e n \& \mathrm{nrm}=$ iso $>$.

Acesso em: 09 ago. 2011. http://dx.doi.org/10.1590/S0102-

69092000000200002

TREVISAN, A. M. QFD: quando o cliente define o produto. Revista Trevisan Conjuntura, Rio de Janeiro, n. 71, p. 34-36, 1998.

URIBE, V. A. V.; CASTELL, A. A. Incidencia de los Factores Sociales en la Salud y la Enfermedad Mental. Revista de Enfermería $R O L$, n. 191-192, p. 65-68, 1994.

WARE, J. E.; KOSINSKI, M.; KELLER, E. D. The SF 16 Psycal and mental Summaru Scales: a user's manual. Boston: The Health Institute.

WARE, J. E.; SHERBOURNE, C. D. The 36 item short-form health survey.I. Conceptual framework and item selection. Med. Care, v. 30, n. 6, p. 473-483, 1992. 